*Doutor em Direito pela Universidade Federal de Pernambuco (UFPE). Mestre em Direito pela Universidade Federal de Alagoas (UFAL). Especialista em Direito pela Universidade Federal de Alagoas (UFAL). Bacharel em Direito pela Universidade Federal de Alagoas (UFAL). Email: marcosehrhardtjr@uol.com.br

\footnotetext{
**Mestrando em Direito pela Universidade Federal de Alagoas (UFAL). Especialista em Direito do Trabalho e Processo do Trabalho pela Damásio Educacional (DAMASIO). Bacharel em Direito pela Universidade Federal de Alagoas (UFAL). Email: luizphillipe. ogmartins@gmail.com
}

\section{A POLÊMICA SOBRE A (IM)POSSIBILIDADE DE REVISTA EM BOLSAS E ARMÁRIOS NA JURISPRUDÊNCIA DO TST}

\author{
THE CONTROVERSIAL (IM)POSSIBILITY OF BAG AND LOCKER \\ SEARCH IN TST CASE LAW
}

\section{Marcos Ehrhardt Junior* Luiz Phillipe de Oliveira Gomes Martins**}

Como citar: EHRHARDT JUNIOR, Marcos. MARTINS, Luiz Phillipe de Oliveira Gomes. A polêmica sobre a (im)possibilidade de revista em bolsas e armários na jurisprudência do TST . Scientia Iuris, Londrina, v. 24, n. 3, p. 73-97, nov. 2020. DOI: 10.5433/2178-8189.2020v24n3p73. ISSN: 2178-8189.

Resumo: $\mathrm{O}$ objeto do presente trabalho é analisar a revista íntima realizada no ambiente de trabalho sobre os pertences pessoais dos trabalhadores, enquanto elemento violador de uma série de normas constitucionais protetivas do empregado. Medologicamente, adota-se no presente trabalho a pesquisa bibliográfica jurídica tocante ao tema e o método lógico dedutivo. Assim, pretendese avaliar o novo paradigma fixado pelo Tribunal Superior do Trabalho (TST), a partir da compreensão de que no cenário apresentado está em questão a inviolabilidade do direito à vida $\mathrm{e}$ à intimidade do trabalhador, o que impõe ao empregador limites do poder fiscalizatório.

Palavras-chave: Dignidade da pessoa humana. Direito do Trabalho. Lei $\mathrm{n}^{\mathrm{o}}$ 13.467/2017. Princípios Constitucionais. Jurisprudência Trabalhista.

\footnotetext{
Abstract: The purpose of this paper is to analyze close inspections in workplace settings - more specifically, the act of searching an employee's personal belongings - as an element that violates a series of constitutional rules protecting worker rights. Methodologically, bibliographic research is used with deductive reasoning. Moreover, the aim of this study is to explore the new paradigm established by the Brazilian Superior Labor Court (TST), which understands that the employee's rights to life and intimacy are violated with close inspections in the workplace. In other words, currently the court's understanding limits employer's supervising power.
} 
Keywords: Dignity of human person. Labor Law. Law $\mathrm{n}^{\circ}$ 13467/2017. Constitutional principles. TST. 


\section{INTRODUÇÃO}

Com a diminuição dos postos de trabalho, a conquista de um novo emprego é o sonho diário de muitos brasileiros. O sucesso obtido com o emprego, normalmente, é algo que deixa qualquer pessoa que estava na "fila de espera" feliz e entusiasmada. Seria a resposta de muitos para assegurar o sustento próprio e o de sua família.

Porém, para alguns trabalhadores, já no primeiro dia inicia-se a decepção com o cenário encontrado, no qual empregadores utilizam condutas abusivas que expõem o trabalhador às situações humilhantes e constrangedoras, com fundamento na prerrogativa de um regular exercício do poder fiscalizatório. É nesse contexto que as frequentes revistas em pertences pessoais enquadram-se como mais uma manifestação do uso excessivo do poder empregatício.

Segundo relatório que divulga os assuntos mais recorrentes na Justiça do Trabalho, levantado pelo Tribunal Superior do Trabalho (TST), no ano de 2018 foram ajuizadas 1.541 (mil quinhentas e quarenta e uma) ações envolvendo as revistas íntimas e em pertences nos funcionários. Em 2019, somente em janeiro e fevereiro, foram registradas 195 (cento e noventa e cinco) novas ações quanto à matéria. O relatório elaborado pelo TST é importante para divulgar os fatos ocorridos diuturnamente no ambiente de trabalho à população.

Os números referidos potencialmente podem ser ainda maiores, já que dificilmente o ajuizamento dessas reclamações trabalhistas ocorre durante o contrato de trabalho, mas tão só após a extinção. Logo, até o ingresso da reclamação trabalhista, a invasão à intimidade já foi promovida. Percebe-se, então, que muitos trabalhadores continuam sendo submetidos a situações humilhantes que atingem profundamente a sua dignidade.

Esta pequena digressão serve para contextualizar o cenário da discussão-objeto do presente texto: estaria dentro do poder fiscalizatório do empregador realizar as revistas em bolsas e armários pessoais dos empregados? O paradigma adotado pelos órgãos da Justiça do Trabalho, seguindo os casos ocorridos no âmbito empresarial, poderia estender-se ao cenário dos contratos domésticos? Seria lícita uma eventual dispensa por justa causa caso seja encontrado um entorpecente nos objetos do empregado?

Percebe-se que o assunto está na ordem do dia, uma vez que, recentemente, o TST fixou um novo parâmetro a ser adotado pelos magistrados da Justiça do Trabalho, sem que tenha considerado inúmeros cenários, como os questionados.

Essa reflexão terá início a partir da análise de um julgado promovido pela $1^{\mathrm{a}}$ turma do TST, a qual seguiu o novo paradigma fixado pela Subseção I Especializada em Dissídios Individuais SBDI I do Tribunal.

\section{CRITÉRIO ESTABELECIDO PELO TST QUANTO ÀS INSPEÇÕES EM BOLSAS E ARMÁRIOS}

No caso julgado pela $1^{\mathrm{a}}$ turma do TST, o empregado apresentou, na reclamação trabalhista, pedido de indenização por dano moral decorrente das revistas sofridas nas bolsas e em seu armário, 
visto que a empresa não tinha demonstrado a necessidade de tais medidas de desconfiança em relação aos funcionários.

A existência das revistas restou incontroversa nos autos, pois a própria reclamada o admitiu na contestação. Embora o juízo de primeiro grau tenha indeferido a indenização por entender que a prática não configurava ofensa à empregada, o Tribunal Regional do Trabalho da $9^{\text {a }}$ Região (PR) reconheceu a responsabilidade da empresa ${ }^{1}$, condenando-a a reparar os danos morais causados à trabalhadora. O Regional mencionou caso análogo julgado naquela Corte, no qual se assinalou que o poder fiscalizatório, também chamado poder de controle, não poderia sobrepor-se à dignidade da pessoa do trabalhador.

A Primeira Turma do Tribunal Superior do Trabalho proveu o Recurso de Revista da WMS Supermercados do Brasil Ltda. (Rede Walmart) contra decisão do Tribunal Regional do Trabalho da $9^{\text {a }}$ Região (PR) que a tinha condenado ao pagamento de indenização por dano moral, no valor de R $\$ 10$ mil, a um empregado que sofria o procedimento de revista em bolsas e armários de 2005 até 2009.

O ponto controvertido consistiu na verificação de se as revistas sofridas nas bolsas e no armário do empregado ultrapassariam os limites do poder fiscalizatório do empregado, sendo assim capazes de causar dano de natureza extrapatrimonial, o que levaria, consequentemente, ao dever de reparação.

Apresenta-se a ementa do julgado proferido pela $1^{\text {a }}$ turma do TST, que decidiu sobre o Recurso de Revista interposto pelo reclamado, mas também sobre o Agravo de Instrumento em Recurso de Revista da Reclamante. Saliente-se que os comentários elaborados em seguida limitarse-ão a analisar a questão debatida quanto à revista em bolsas e armários, bem como o aspecto relativo à responsabilidade civil e à eventual indenização por dano moral, a fim de contribuir para uma reflexão que leve a soluções do problema em debate.

RECURSO DE REVISTA INTERPOSTO PELO RECLAMADO ANTERIORMENTE À VIGÊNCIA DA LEI No 13.105/2014. REVISTA EM BOLSAS E ARMÁRIOS. INDENIZAÇÃO POR DANO MORAL. PRESUNÇÃO. ÔNUS DA PROVA. I - A jurisprudência desta Corte Superior é firme no sentido de que o procedimento de revistas realizado nos pertences pessoais de todos os empregados, indiscriminadamente, sem contato físico, insere-se no âmbito do poder diretivo e fiscalizatório do empregador, não gerando constrangimento apto a ensejar dano moral indenizável. II - Na hipótese, contudo, o quadro fático delineado no acórdão regional permite constatar que

1 O Tribunal Regional da $9^{a}$ deu provimento ao recurso ordinário da reclamante mediante os seguintes fundamentos destacados: "A sentença entendeu não haver ofensa à imagem da trabalhadora devido à sua submissão à revista de bolsas e armários no fim da jornada, não se equiparando à revista íntima [...]. A autora pugna pelo reconhecimento de danos morais decorrentes das revistas, por parte da ré, eis que não foi demonstrada a necessidade de tais medidas de desconfiança em relação aos funcionários. Com razão [...]. Não se pode olvidar que o ordenamento jurídico brasileiro consagra a dignidade da pessoa humana como fundamento da República (CF, art. $1^{\circ}$, III) [...]. A revista na bolsa e nos pertences dos empregados não se revela necessária, mormente quando a tecnologia fornece outros meios não constrangedores para a segurança do patrimônio do empregador (etiquetas eletrônicas, filmadoras, etc.) [...]. Há que imperar uma proporcionalidade na sua aplicação, nada justificando o tratamento dispensado em relação aos empregados, que ora são tratados como colaboradores, ora como criminosos [...]. Logo, a ocorrência de revistas, sem demonstração de efetiva necessidade, autoriza a presunção de dano moral sofrido". 
as revistas em bolsas e armários não eram dirigidas somente à reclamante, nem implicavam contato físico de qualquer natureza, não é possível presumir dano moral. Ao assim fazê-lo, sem que demonstrados os elementos suficientes à caracterização do ato ilícito, o Tribunal Regional contrariou a jurisprudência dominante nesta Corte Superior, violando o art. 818 da CLT. Recurso de revista conhecido e provido. [...]. (TST - ARR 640-34.2011.5.09.0004, Relator Ministro: Walmir Oliveira da Costa, Data de Julgamento: 21/11/2018, $1^{\text {a }}$ Turma, Data de Publicação: 23/11/2018).

O TST possui oito turmas. O julgado proferido pela $1^{\text {a }}$ Turma do Tribunal entendeu que o procedimento de revistas realizado nos pertences pessoais, o que muitos denominam de revistas pessoais para diferenciar de revistas íntimas, por ser realizado sem contato físico e de forma indiscriminada, insere-se no âmbito do poder fiscalizatório do empregador, concluindo desse modo que não há constrangimento capaz de gerar dano moral indenizável.

Importante destacar que, quanto à matéria, há pouco tempo o próprio TST não tinha pacificado o entendimento sobre os limites e critérios para a realização das inspeções nos pertences pessoais dos empregados. Nesse sentido, vale destacar julgado da $3^{\text {a }}$ Turma do TST, a qual, mesmo de forma isolada entre as turmas deste Tribunal Superior, posicionava-se em sentido contrário ao apresentado pela $1^{\text {a }}$ Turma, in verbis:

RECURSO DE REVISTA. 1. MULTA DO ART. 477 DA CLT. ATRASO NA ENTREGA DAS GUIAS. INDEVIDA. [...]. 2. REVISTA (AINDA QUE MODERADA)DEBOLSASESACOLAS.DANOMORAL.CONFIGURAÇÃO. 1.1. [...]. Nesse contexto, e sob uma interpretação sistemática dos preceitos legais e constitucionais aplicáveis à hipótese, entende-se que a revista diária em bolsas e sacolas, por se tratar de exposição contínua do empregado a situação constrangedora no ambiente de trabalho, que limita sua liberdade e agride sua imagem, caracterizaria, por si só, a extrapolação daqueles limites impostos ao poder fiscalizatório empresarial, mormente quando o empregador possui outras formas de, no caso concreto, proteger seu patrimônio contra possíveis violações. Nesse sentido, as empresas, como a Reclamada, têm plenas condições de utilizar outros instrumentos eficazes de controle de seus produtos, como câmeras de filmagens e etiquetas magnéticas. Tais procedimentos inibem e evitam a violação do patrimônio da empresa e, ao mesmo tempo, preservam a honra e a imagem do trabalhador- (Ministro Mauricio Godinho Delgado). 1.2. A jurisprudência da Eg. $3^{\text {a }}$ Turma evoluiu para compreender que a revista dita moderada em bolsas e sacolas de trabalhadores, no início ou ao final da jornada de trabalho, mesmo que sem contato físico ou manipulação de pertences, provoca dano moral e autoriza a condenação à indenização correspondente. Ressalva de ponto de vista do Relator. Recurso de revista conhecido e desprovido. [...]. (TST - RR - 62362.2011.5.09.0015, Relator Ministro: Alberto Luiz Bresciani de Fontan Pereira, Data de Julgamento: 17/9/2013, $3^{a}$ Turma, Data de Publicação: 20/9/2013).

Segundo a decisão representativa da $3^{\text {a }}$ Turma do TST, verifica-se uma posição contrária a toda conduta fiscalizatória que possa agredir a dignidade e a liberdade do trabalhador, 
tendo como base a própria Constituição Federal de 1988 (CF/1988). Defende o julgado que esse tipo de inspeção promovida pelo empregador vai de encontro às normas constitucionais responsáveis por salvaguardar um Estado Democrático de Direito, em especial, normas que asseguram o direito à vida e à liberdade (art. $5^{\circ}$, caput); a vedação a qualquer tipo de tratamento desumano e degradante (art. $5^{\circ}$, III); como, também, a regra que enuncia serem "invioláveis a intimidade, a vida privada, a honra e a imagem da pessoa, assegurado o direito à indenização pelo dano material ou moral decorrente de sua violação" (art. 5º X) (BRASIL, 1988).

Registre-se que esse conjunto de regras desenvolve uma fronteira limitadora ao poder fiscalizatório do empregador nas relações de trabalho, colocando as medidas que cerceiam a liberdade e a dignidade do prestador de serviços em franca contrariedade ao sistema jurídico.

No mesmo sentido, a I Jornada de Direito Material e Processual na Justiça do Trabalho ${ }^{2}$ elaborou o Enunciado 15, a seguir:

I - REVISTA - ILICITUDE. Toda e qualquer revista, íntima ou não, promovida pelo empregador ou seus prepostos em seus empregados e/ou em seus pertences, é ilegal, por ofensa aos direitos fundamentais da dignidade e intimidade do trabalhador.

II - REVISTA ÍNTIMA - VEDAÇÃO A AMBOS OS SEXOS. A norma do art. 373-A, inc. VI, da CLT, que veda revistas íntimas nas empregadas, também se aplica aos homens em face da igualdade entre os sexos inscrita no art. $5^{\circ}$, inc. I, da Constituição da República (BRASIL, 2007).

O enunciado $\mathrm{n}^{\circ} 15$, elaborado pela comissão que tratou das matérias atinentes aos direitos fundamentais e às relações de trabalho, mostrava-se como um grande auxílio para afastar qualquer tipo de revista no ambiente de trabalho. $\mathrm{O}$ referido enunciado na $2^{\mathrm{a}}$ parte ratificou entendimento que já se verificava nos precedentes do TST, aplicando-se a vedação da revista íntima a ambos os sexos, considerando o princípio da isonomia, mas, sobretudo, contribuindo para a efetividade do fundamento constitucional da dignidade humana.

$\mathrm{Na} 1^{\mathrm{a}}$ parte, o enunciado apresentou orientação contribuindo com o entendimento de afastar qualquer tipo de revista, expondo de forma cristalina que as revistas realizadas sobre os pertences pessoais deveriam ser consideradas ilegais por ofenderem os direitos fundamentais do trabalhador. Ainda que os enunciados não possuam efeitos vinculantes, foram desenvolvidos com o objetivo de demonstrar como pensavam e deveriam aplicar os operadores do direito.

Percebe-se que essa ideia de reconhecer ilícita todo tipo de revista, íntima ou não, também repercutia nas decisões de alguns Tribunais Regionais do Trabalho (TRT), conforme se observa no julgado proferido pelo TRT da $19^{\text {a }}$ Região (AL):

2 A I Jornada de Direito Material e Processual na Justiça do Trabalho foi realizada em 2007 para discutir questões do Direito do Trabalho e outras matérias correlacionadas à competência do Judiciário Trabalhista. Foi resultado de uma reunião organizada pela Escola Nacional de Formação e Aperfeiçoamento de Magistrados do Trabalho (ENAMAT), Associação Nacional dos Magistrados do Trabalho (ANAMATRA) e pelo Tribunal Superior do Trabalho (TST). A jornada reuniu operadores do direito de diversos ramos: advogados, bacharéis em Direito, juízes e procuradores do MPT para discutir matérias relevantes do direito do Trabalho, uma delas as revistas em empregados. 
[...]. A REVISTA EM TRABALHADORES, SEJA ATRAVÉS DE CONTATO FÍSICO OU EM BOLSAS E PERTENCES, É UMA PRÁTICA QUE JÁ DEVERIA TER SIDO ABOLIDA NOS TEMPOS ATUAIS, ESPECIALMENTE NAS GRANDES EMPRESAS, QUANDO A TECNOLOGIA PERMITE AO EMPREGADOR PROTEGER MELHOR O SEU PATRIMÔNIO SEM, CONTUDO, CONSTRANGER E NEM EXPOR A INTIMIDADE DAQUELE QUE LHE PRESTA SERVIÇOS. O DIREITO DA EMPRESA DE DEFENDER O SEU PATRIMÔNIO NÃO PODE VIOLAR OUTRO NÃO MENOS IMPORTANTE, OU MELHOR, MAIS IMPORTANTE E GARANTIDO CONSTITUCIONALMENTE, QUE É O DIREITO À INTIMIDADE E À HONRA (ART. $5^{\circ}, \mathrm{X}, \mathrm{CF} / 88$ ), VALENDO RESSALTAR QUE A DIGNIDADE DA PESSOA HUMANA É UM DOS FUNDAMENTOS DA REPÚBLICA FEDERATIVA DO BRASIL (ART. $1^{\circ}$, III, CF/88). RECURSO PROVIDO. (TRT/ AL - RO: 0001226-83.2011.5.19.0007, Relator: João Leite. Data de Publicação: 13/8/2013).

Registre-se que, posteriormente, em 2017, o TRT da $19^{a}$ Região (AL), por meio da Súmula $\mathrm{n}^{\mathrm{o}} 7^{3}$, concluiu que a revista meramente visual não viola o direito de personalidade, unificando a matéria nesse tribunal.

Recentemente, a matéria aportou mais uma vez na $3^{\mathrm{a}}$ Turma do $\mathrm{TST}^{4}$, o que demonstra a relevância e a instabilidade sobre o assunto, contudo, agora, posicionou-se seguindo o entendimento majoritário consolidado no TST. Em análise ao inteiro teor, constata-se que, no último julgado da $3^{\text {a }}$ Turma, esta seguiu a pacificação jurisprudencial promovida pela Subseção I Especializada em Dissídios Individuais - SBDI I - do TST, visto que, conforme já observado, apenas a Turma em comento apresentava posicionamento em sentido contrário. Frise-se que, indo de encontro ao paradigma fixado, o ministro Relator apresentou uma ressalva que demonstra a "turbulência" por que passa a matéria, in verbis: "Ressalva de compreensão deste Relator, que considera ter havido, sim, afronta a bens imateriais do trabalhador (dignidade, privacidade e honra, por exemplo). Mas não é essa a jurisprudência dominante no TST" (BRASIL, 2012).

Evidentemente, os diversos posicionamentos que se verificam nos julgados também se refletem na doutrina, a qual evidencia um diálogo constante sobre a situação apresentada (revistas em pertences pessoais), isto é, a doutrina procura analisar os limites do poder fiscalizatório sem que se exponha o trabalhador à situação humilhante e constrangedora.

3 REVISTA ÍNTIMA. DANO MORAL. CONFIGURAÇÃO. I - Submeter o empregado a revistas íntimas em seus pertences pessoais viola direitos da personalidade do trabalhador assegurados constitucionalmente $\left(\operatorname{art} .5^{\circ}, \mathrm{X}, \mathrm{CF}\right), \mathrm{o}$ que implica a existência de dano moral e o pagamento da correspondente indenização. II - A mera revista visual dos pertences do trabalhador não constitui violação ao direito da personalidade do empregado, logo não configura dano moral, nem dá lugar a pagamento de indenização.

4 [...] B) RECURSO DE REVISTA DO RECLAMANTE. PROCESSO SOB A ÉGIDE DA LEI 13.015/2014 E ANTERIOR À LEI 13.467/2017. DANO MORAL. REVISTA IMPESSOAL E INDISCRIMINADA EM BOLSAS E SACOLAS. AUSÊNCIA DE CONTATO FÍSICO ÍNTIMO. NÃO CONFIGURAÇÃO DE VIOLAÇÃO À INTIMIDADE, À DIGNIDADE OU À HONRA DO RECLAMANTE. IMPROCEDÊNCIA DE INDENIZAÇÃO. Em função da pacificação jurisprudencial promovida pela SBDI-1 do TST, prevalece, nesta Corte, o entendimento de que a simples revista visual de bolsas e sacolas, desde que sem contato físico, não enseja indenização por dano moral [...]. Nesse sentido é o entendimento da SBDI-1 do TST, que não considera cabível indenização por dano moral em decorrência de simples revista de bolsas e sacolas. Ressalva da compreensão do Relator. Recurso de revista conhecido e provido. (TST - ARR -1111-68.2012.5.09.0892, Relator Ministro: Mauricio Godinho Delgado, Data de Julgamento: 27/2/2019, $3^{\text {a }}$ Turma, Data de Publicação: 1/3/2019). 
Nesta esteira de violação a direitos fundamentais no ambiente laboral, observa-se que o legislador não estabeleceu expressamente os limites pelos quais o empregador deve pautar-se quando das atribuições de seu poder diretivo no momento de realizar as inspeções sobre os objetos pessoais dos trabalhadores.

Indaga-se, portanto, se as revistas íntimas e pessoais no ambiente de trabalho devem ou não ser toleradas, devendo-se sopesar a colisão entre direito e intimidade do empregado, mas também o poder diretivo e o direito de propriedade do empregador, assim como até que ponto o empregador tem o poder de inspecionar os objetos pessoais dos trabalhadores, os quais são capazes de gerar danos na esfera extrapatrimonial do prestador de serviços.

A temática em pauta tem raízes interdisciplinares, de tal modo que navega, a partir do direito do trabalho, pelo direito constitucional e pelo direito civil, visando à análise sobre a possibilidade de o empregador realizar revista pessoal no ambiente de trabalho, porém sem colocar em xeque a efetivação dos direitos humanos na relação intersubjetiva laboral.

\section{A INVIOLABILIDADE DO DIREITO À VIDA E À INTIMIDADE DO TRABALHADOR}

Não se pode perder de vista que o trabalho é um dos aspectos essenciais à existência humana. Nesse sentido, a violação aos direitos constitucionais, base do sistema normativo brasileiro, desestrutura, em parte, todo o sistema jurídico. Logo, na análise do instituto, o operador do direito não se limita unicamente ao conjunto de normas infraconstitucionais.

Ainda que a $\mathrm{CF} / 1988$ descreva inúmeros direitos fundamentais relevantes, como no artigo $7^{\circ}$, que aborda a não discriminação (art. $7^{\circ}, \mathrm{XXX}, \mathrm{XXXI}$, e XXXII), e o da continuidade da relação de emprego (art. $7^{\circ}, \mathrm{I}$ e XXI), no âmbito da discussão apresentada, o direito à vida e o direito à intimidade do trabalhador, que se apresentam como facetas intrínsecas ao princípio da dignidade do ser humano, merecem destaque.

Leciona Gabriela Neves Delgado:

[...] o trabalho não violará o homem enquanto fim em si mesmo, desde que prestado em condições dignas. O valor da dignidade deve ser o sustentáculo de qualquer trabalho humano... Onde o direito ao trabalho não for minimamente assegurado (por exemplo, com respeito à integridade física e moral do trabalhador, o direito à contraprestação pecuniária mínima), não haverá dignidade humana que sobreviva. (DELGADO, 2006, p. 207).

A vida privada e a intimidade apresentam-se como valores indispensáveis que devem ser preservados para se garantir um ambiente de trabalho digno e livre de tensões entre empregados e empregadores (RIBAR, 2006, p. 1095).

Segundo Rabindranath Valentino Aleixo Capelo de Souza (1995, p. 106): 
[...] a personalidade surge aqui imediatizada no ser humano e configurada como objeto de direitos e deveres, não se perspectivando como elemento qualificador do sujeito da relação jurídica, enquanto tal, cuja qualificação nos é dada antes pelas ideias de personalidade jurídica, ou seja, pelo reconhecimento de um centro autônomo de direitos e obrigações.

Verifica-se que a liberdade individual fundamenta o próprio direito à intimidade, já que, conforme assevera Leda Maria Messias da Silva (2006, p. 68), “abrange fatos da vida pessoal do indivíduo que até mesmo sua própria família pode desconhecer, como, por exemplo, suas preferências sexuais, hábitos, vícios, entre outros".

Como imaginar qual item pode ser encontrado durante uma inspeção nas bolsas e armários? Não se pode negar que, dentro de bolsas, mochilas e armários, podem estar protegidos toda a intimidade e segredos que até amigos mais próximos ou familiares ignoram.

Ressalte-se, desde já, que embora o direito à intimidade e o direito à vida privada estejam inseridos na ideia de privacidade, eles não se confundem. O constituinte, expressamente, deu amplitude diversa aos enunciados intimidade e vida privada, inclusive, separando-os no art. $5^{\circ}, \mathrm{X}$, CF: " $\mathrm{X}$ - são invioláveis a intimidade, a vida privada, a honra e a imagem das pessoas, assegurado o direito à indenização pelo dano material ou moral decorrente de sua violação" (BRASIL, 1988).

Assim, entende-se que intimidade e vida privada são valores aproximados, porém distintos. A intimidade está relacionada com o mais íntimo da pessoa, algo interno. Assim,

Os conceitos constitucionais de intimidade e vida privada apresentam grande interligação, podendo, porém, ser diferenciados por meio da menor amplitude do primeiro, que se encontra no âmbito de incidência do segundo. Assim, o conceito de intimidade relaciona-se às relações subjetivas e de trato íntimo da pessoa humana, suas relações familiares e de amizade, enquanto o conceito de vida privada envolve todos os relacionamentos da pessoa, inclusive os objetivos, tais como relações comerciais, de trabalho, de estudo etc. (MORAES, 2005, p. 125).

No mesmo sentido, a diferença entre intimidade e vida privada é que a primeira estaria relacionada aos "segredos mais recônditos do indivíduo", como, por exemplo, a própria opção sexual e a vida amorosa, enquanto a vida privada seria algo menos secreto, ligado à vida de relações com amigos e familiares, o que não afastaria a exigência de proteção em face de terceiros (CUNHA JÚNIOR, 2009, p. 680).

O artigo XII da Declaração Universal dos Direitos Humanos dispõe, no que concerne à vida privada, que “[...] ninguém será sujeito a interferências na sua vida privada [...]. Toda pessoa tem direito à proteção da lei contra tais interferências ou ataques".

No sistema brasileiro, essa proteção não se restringe à $\mathrm{CF} / 1988$, conforme descrito no artigo 5 $5^{\circ}$, inciso X. O vigente Código Civil de 2002 (CC/2002) também trata dos direitos da 
personalidade em seus dispositivos, dos quais se destacam os artigos 11 e 21:

Art. 11, CC: Com exceção dos casos previstos em lei, os direitos da personalidade são intransmissíveis e irrenunciáveis, não podendo o seu exercício sofrer limitação voluntária.

Art. 21, CC: A vida privada da pessoa natural é inviolável, e o juiz, a requerimento do interessado, adotará as providências necessárias para impedir ou fazer cessar ato contrário a esta norma. (BRASIL, 2002).

Importante destacar que, nos termos do parágrafo primeiro do artigo $8^{\circ}$ da Consolidação das Leis do Trabalho (CLT), o direito comum é aplicado de forma subsidiária ao Direito do Trabalho. Assim, outros dispositivos infraconstitucionais do Código Civil devem ser aplicados para assegurar o mínimo de dignidade ao empregado, em especial quando envolver violação à intimidade e à vida privada.

Nesse cenário, o gosto pessoal do trabalhador, as amizades e, inclusive, o lixo produzido fazem parte da intimidade e vida privada, interessando exclusivamente à pessoa do trabalhador, devendo ficar longe da intromissão, interferência ou curiosidade de quem quer que seja - aqui, no caso, fora dos "olhares" do empregador (MONTEIRO, 2003, p. 99).

Não resta dúvida que a inspeção realizada em pertences pessoais e nos armários destinados à guarda dos objetos do empregado adentra na esfera da intimidade e da vida privada, seja a revista constatada na presença de clientes ou não.

Registre-se que a sociedade, com destaque para os operadores do direito, deve ficar atenta para que no ambiente de trabalho não se privem os direitos de intimidade e a vida privada dos empregados, os quais não são retirados, muito menos, renunciados a partir da sujeição ao poder diretivo no momento da contratação.

\section{OS LIMITES DO PODER FISCALIZATÓRIO DO EMPREGADOR E A PROPORCIONALIDADE DO MEIO UTILIZADO}

Como é possível extrair dos julgados já citados, mas também do número de ações ajuizadas envolvendo a matéria, não se pode negar a ocorrência cada vez mais frequente das inspeções de pertences pessoais dos empregados nos estabelecimentos empresariais como consequência lógica dos usos e costumes.

Nesse cenário de revistas pessoais aos bens dos prestadores de serviços, o poder fiscalizatório que incide sobre a atividade exercida vai de encontro ao direito à intimidade e à vida privada dos empregados. O controle realizado pelo tomador de serviços representa um instrumento para a materialização do direito de propriedade previsto constitucionalmente. (art. $5^{\circ}$, XXII e XXIII; art. 170, II e III): “[...] XXII - é garantido o direito de propriedade; XXIII - a propriedade atenderá a sua função social". Porém, não é possível admitir qualquer prática fundamentada no direito de propriedade privada que agrida a dignidade do trabalhador. É por esse motivo que o meio escolhido deve ser proporcional para atingir o fim pretendido. 
Ciente da importância do princípio da proporcionalidade para a verificação, no caso concreto, das restrições aos direitos fundamentais, sendo a revista, íntima ou não, uma forma de ingerência do empregador à intimidade e à vida privada do empregado, a necessidade de sua aplicação no controle das inspeções no ambiente de trabalho apresenta-se evidente.

Essa aplicação da proporcionalidade, conforme formulação de Barroso (2011, p. 329), deve atentar a três subprincípios, sob pena de invalidação do ato. Quando

a) não haja adequação entre o fim perseguido e o instrumento empregado (adequação); b) a medida não seja exigível ou necessária, havendo meio alternativo menos gravoso para chegar ao mesmo resultado (necessidade/vedação do excesso); c) os custos superem os benefícios, ou seja, o que se perde com a medida é de maior relevo do que aquilo que se ganha (proporcionalidade em sentido estrito).

No julgado em análise, ao admitir a revista nas bolsas e armários dos funcionários, o que o TST fez foi analisar o direito de propriedade exercido através do poder fiscalizatório, de acordo com a proporcionalidade, isto é, verificou se o meio foi adequado, necessário e proporcional para realizar o fim legítimo (proteção do estabelecimento do empregador), chegando à conclusão de que o ato era válido. Questiona-se: a medida é proporcional?

Como visto, a adequação representa a relação entre a realização do fim pretendido e o meio eleito. Neste ponto, não se nega que a medida patronal de revistar é capaz de fomentar a proteção dos bens que o empregador pretende proteger. Portanto, atingido esse objetivo, a medida apresenta-se adequada.

Por outro lado, não se pode responder de forma direta e objetiva quanto à necessidade. Segundo Humberto Ávila (2010, p. 172), o subprincípio da necessidade refere-se à observação da existência de medidas que possam aparecer como alternativas à inicialmente escolhida, no caso, a prática das revistas pessoais pelo empregador, e que possam, na mesma proporção, atingir o objetivo pretendido, sem restringir, com o mesmo grau de intensidade, os direitos fundamentais afetados.

Antes de admitir a prática das revistas pessoais aptas a interferir na intimidade dos empregados, o tomador de serviços deveria considerar outros meios disponíveis para ver satisfeita a proteção ao seu patrimônio. Evidentemente, avaliando as condições estruturais e financeiras de cada empreendimento, podem ser obtidos mecanismos alternativos menos agressivos para se chegar ao mesmo resultado. Cite-se, por exemplo, a utilização de câmaras audiovisuais ou microchips instalados nos produtos.

Dessa maneira, havendo meio alternativo às revistas, as inspeções nos bens particulares dos prestadores de serviços serão consideradas desproporcionais, por desnecessárias. Percebe-se, então, que incumbiria ao empregador o ônus de provar que não existem outros meios viáveis para atingir ao fim pretendido.

No que toca à proporcionalidade em sentido estrito, segundo os ensinamentos de Pedro Adamy (2011, p. 181), cabe comparar “entre a importância da realização do fim e a intensidade 
da interferência ou restrição no direito fundamental". Nesse quesito, as revistas também são desproporcionais, já que essa prática restringe excessivamente a intimidade e a vida privada dos empregados em comparação com o objetivo buscado (a proteção do patrimônio do empregador). Assim, não há margem para a aceitação dessa conduta.

Nessa toada, o princípio da proporcionalidade atua como verdadeiro instrumento limitativo do poder fiscalizatório do empregador, bem como um meio para combater a falta de equilíbrio contratual, pois se defende que os direitos fundamentais dos prestadores de serviços só devem sofrer restrições quando estas forem proporcionais ou se mostrarem imprescindíveis no caso concreto. Perceptivelmente, não basta a mera adequação do meio para que a empresa justifique a restrição ao direito de intimidade.

Atente-se que não se defende o sacrifício total do poder fiscalizatório do empregador, mas sim a harmonização com os direitos fundamentais dos trabalhadores, caso contrário, a revista diariamente exercida sobre as bolsas e armários caracterizará exposição contínua do empregado à situação constrangedora no ambiente de trabalho, agredindo a intimidade, a vida privada e a liberdade do empregado.

\section{ANÁLISE DAS DIFERENTES TESES QUANTO À ACEITABILIDADE DAS REVISTAS SOBRE PERTENCES PESSOAIS E ARMÁRIOS}

Na doutrina, é possível extrair quatro posicionamentos distintos a respeito da possibilidade ou não da revista pessoal. A primeira defende que o simples fato de não existir previsão legal disciplinando a revista pessoal autorizaria tal ato pelo empregador, desde que previsto no regimento interno da empresa. Os defensores dessa teoria entendem que a revista nos bens dos empregados ao final da jornada não é suficiente para gerar direito a uma indenização por danos morais, visto que alegam não existir violação à intimidade ou à privacidade do trabalhador. Portanto, desde que não haja contato com o corpo do trabalhador, para esta vertente, a revista nos prestadores de serviços está permitida.

Nesse caminho, percebe-se que alguns doutrinadores como José Eduardo Duarte Saad e Ana Maria Saad Castelo Branco, que fazem uma interpretação restrita e literal do artigo 373-A, inciso VI, da CLT ${ }^{5}$, argumentando que a previsão do referido artigo deve ser aplicada quando da revista íntima e às mulheres (apud NUNES, 2011, p. 69). Esta primeira corrente não representa a teoria majoritária dos doutrinadores e juristas acerca da revista dita pessoal.

A segunda vertente, que é a mais difundida no âmbito jurídico, caminha no sentido de permitir a referida prática. Reflete-se no julgado da $1^{\text {a }}$ Turma do TST e foi consolidada pela SBDI I - do TST, como já apontado. Segundo essa posição, não se exclui a possibilidade da realização das revistas em objetos dos trabalhadores, desde que se observem critérios específicos no momento das inspeções.

5 Vide o Art. 373-A da CLT: “Art. 373-A. Ressalvadas as disposições legais destinadas a corrigir as distorções que afetam o acesso da mulher ao mercado de trabalho e certas especificidades estabelecidas nos acordos trabalhistas, é vedado: [...] VI - proceder o empregador ou preposto a revistas íntimas nas empregadas ou funcionárias". 
Um dos seguidores deste posicionamento é Amauri Mascaro Nascimento, o qual entende ser necessário verificar o caso concreto para que se observe se ocorreu invasão da intimidade do trabalhador. Afirma ser possível a revista pessoal desde que não seja íntima e não viole a dignidade do empregado (NASCIMENTO, 2006, p. 494-495).

No mesmo sentido, esclarece Sérgio Pinto Martins (2009, p. 198):

O empregador tem o direito de fiscalizar e controlar as atividades de seus empregados. Os empregados poderão ser revistados no final do expediente. A revista do empregado é uma forma de salvaguarda do patrimônio da empresa. Não poderá ser a revista feita de maneira abusiva ou vexatória, ou seja, deverá ser moderada. Vedada será a revista que violar a intimidade do empregado (art. $5^{\circ}, \mathrm{X}$, da Constituição), além do que ninguém será submetido a tratamento desumano ou degradante (art. $5^{\circ}$, III, da Lei Magna). A revista não pode ser realizada em local não apropriado e na presença de clientes, pois se torna vexatória.

Alice Monteiro Barros adota essa posição; além de fundamentar as revistas pessoais como uma forma de salvaguardar o patrimônio do empregador, defende a necessidade da utilização de critérios que legitimem a revista nos objetos ou locais restritos aos empregados. Assim,

[...] quando utilizada, a revista deve ser de caráter geral, impessoal, para evitar suspeitas, através de critério objetivo (sorteio, numeração, todos os integrantes de um turno ou setor), mediante ajuste prévio com a entidade sindical ou com o próprio empregado, na falta daquele, respeitando-se, ao máximo, os direitos da personalidade (intimidade, honra, entre outros). (BARROS, 1997, p. 74).

Essa corrente que entende ser válida a revista pessoal (ou dos pertences) do empregado prevê alguns limites para a realização da inspeção apenas em situações excepcionais, sendo recomendado que: ocorra no local de trabalho, valendo-se de critérios objetivos; exista previsão em regimento interno da empresa; seja feita em todos os empregados, ou, não sendo possível, que se selecione de forma aleatória; por pessoa do mesmo sexo; bem como, estabeleçam-se determinadas garantias aos funcionários com o intuito de impedir abusos pelo empregador. Note-se que a solução dada por essa corrente, a qual só permite a revista pessoal após atender a uma série de critérios, por si só, não salvaguarda a dignidade e a intimidade do empregado. Como observado, essa teoria se reflete na maioria dos julgados no âmbito da Justiça do Trabalho.

Doutra banda, encontra-se a posição que reputa inválida qualquer tipo de revista realizada no empregado. Na terceira vertente, o entendimento doutrinário e jurisprudencial defende que a prática de inspeções pessoais não é imprescindível na proteção do patrimônio empresarial, porém, uma vez realizada, viola o direito à intimidade do trabalhador. Destarte, não existem dúvidas em afirmar que, na ponderação entre os valores e direitos em conflito - propriedade e intimidade -, neste caso, deverá prevalecer o segundo, por se entender inadmissível a revista pessoal em 
qualquer situação (VIDAL; ANELLO, 2008, p. 114).

Percebe-se que, enquanto a segunda corrente tem aceitado a revista nos bens pessoais dos empregados (sacolas, bolsas, armários etc.) sob certos limites já apontados, a terceira, defendida por autores como Maurício Godinho Delgado e Carolina Tupinambá, reconhecendo que a matéria envolve múltiplos interesses tutelados pela Constituição da República (a título ilustrativo: intimidade, vida privada, dignidade da pessoa humana, presunção de inocência e direito de propriedade), nega a legitimidade de toda forma de revista, seja sobre o corpo, seja sobre os objetos pessoais (TUPINAMBÁ, 2018, p. 110).

Ainda é possível apontar uma quarta posição, apresentada por Rosana Marques Nunes, a qual se coloca entre a segunda e a terceira corrente doutrinária, já que apresenta um parâmetro adicional aos defendidos pela corrente majoritária: a inexistência de outro meio tecnológico capaz de controlar o patrimônio do empregador. A autora defende que não havendo outra solução por meio da tecnologia, seria possível o empregador valer-se das revistas pessoais (NUNES, 2011, p. 119).

Cumpre salientar que no campo legislativo, ainda que tenha sido editada a Lei $\mathrm{n}^{\mathrm{o}}$ 13.271/2016 ${ }^{6}$, que proíbe a revista íntima de funcionárias nos locais de trabalho, a matéria ainda gera dúvidas que suscitam maiores estudos, já que a referida norma não disciplinou os limites das inspeções sobre os objetos pessoais dos trabalhadores. A referida Lei apenas inovou ao prever multa administrativa ao empregador que desrespeitar o disciplinado no art. $1^{\circ}$. Portanto, poderão ser verificados futuros debates quanto à inclusão ou não do enunciado revista pessoal no sentido de revista íntima, a qual está vedada de forma expressa no sistema jurídico brasileiro.

Registre-se que o Projeto de Lei $n^{0}$ 583, de 2007, posteriormente transformado na Lei Ordinária 13.271/2016, é explícito ao demonstrar que o objetivo do projeto consistia em "garantir e assegurar à mulher o direito ao trabalho sem ter sucessivamente sua intimidade violada". Destarte, ainda que a Lei $n^{\circ} 13.271 / 2016$ não tenha disciplinado os limites das inspeções sobre os objetos pessoais dos trabalhadores, ela procurou reforçar a necessidade de se proibir a revista íntima no ambiente de trabalho, assim, promovendo a proteção do direito fundamental à intimidade.

Essa indeterminação legal pode fazer com que o paradigma fixado tenha repercussão em outras relações de trabalho, as quais não aparentam terem sido consideradas pelo TST. Aqui, destaque-se o trabalho doméstico, disciplinado pela Lei Complementar $n^{\circ} 150$, de 2015, a qual não dispõe sobre eventual prática de inspeção sobre os pertences pessoais.

A posição fixada que entende legais as revistas de forma indiscriminada é suficiente para assegurar ao empregador doméstico que pratique, diariamente, o ato fiscalizatório nos bens pessoais dos prestadores de serviços no ambiente domiciliar. Aqui, reiteram-se as críticas feitas, já que o

6 Vide a Lei $\mathrm{n}^{\circ}$ 13.271/2016: “Art. $1^{\circ}$ As empresas privadas, os órgãos e entidades da administração pública, direta e indireta, ficam proibidos de adotar qualquer prática de revista íntima de suas funcionárias e de clientes do sexo feminino. Art. $2^{\circ}$ Pelo não cumprimento do art. $1^{\circ}$, ficam os infratores sujeitos a: I - multa de R\$ 20.000,00 (vinte mil reais) ao empregador, revertidos aos órgãos de proteção dos direitos da mulher; II - multa em dobro do valor estipulado no inciso I, em caso de reincidência, independentemente da indenização por danos morais e materiais e sanções de ordem penal”. 
ato pode ser considerado arbitrário, porquanto é desproporcional para a proteção do patrimônio particular do empregador.

E o que pensar de trabalhadores adolescentes ${ }^{7}$ ? Seja uma típica relação de emprego, estagiário ou aprendiz, a atenção não pode estar afastada das relações trabalhistas com prestadores de serviços entre 14 e 18 anos de idade, os quais ainda se encontram no processo de amadurecimento psicofísico. Essa condição especial torna imperioso o combate a qualquer conduta que possa prejudicar o pleno desenvolvimento desses trabalhadores.

Nesse cenário, a Constituição de 1988 deu especial atenção no art. 227:

Art. 227. É dever da família, da sociedade e do Estado assegurar à criança, ao adolescente e ao jovem, com absoluta prioridade, o direito à vida, à saúde, à alimentação, à educação, ao lazer, à profissionalização, à cultura, à dignidade, ao respeito, à liberdade e à convivência familiar e comunitária, além de colocálos a salvo de toda forma de negligência, discriminação, exploração, violência, crueldade e opressão.

$[\ldots]$

$\S 3^{\circ} \mathrm{O}$ direito a proteção especial abrangerá os seguintes aspectos:

I - idade mínima de quatorze anos para admissão ao trabalho, observado o disposto no art. $7^{\circ}, \mathrm{XXXIII;}$

II - garantia de direitos previdenciários e trabalhistas;

$[\ldots]$

$\S 4^{\circ}$ A lei punirá severamente o abuso, a violência e a exploração sexual da criança e do adolescente.

A partir do texto constitucional, constata-se a proteção compartilhada entre todos os membros da sociedade; cabe também aos empregadores promover uma especial proteção aos trabalhadores menores de 18 anos de idade. No mesmo caminho, com o intuito de assegurar a efetividade à $\mathrm{CF} / 1988$, as normas infraconstitucionais contribuem nessa proteção, merecendo destaque os arts. 402 a 441 da CLT, que trazem um conjunto normativo para afastá-los de todo risco à saúde no ambiente de trabalho, mas também a Lei nº 8.069, de 1990 (Estatuto da Criança e do Adolescente), que estabelece diretrizes para uma proteção integral dos adolescentes.

A mesma violação através das revistas sobre pertences pessoais, se mantido o paradigma estabelecido, será suportada por pessoas com deficiência, que exigem atendimento especial no trabalho. A garantia às normas do sistema jurídico envolve os procedimentos adotados que se relacionam à proteção da segurança e à saúde desses trabalhadores.

Nessa seara, o legislador instituiu a Lei $n^{\circ}$ 13.146/2015 (Estatuto da Pessoa com Deficiência), considerada um microssistema que engloba diversas matérias jurídicas, com destaque aos direitos de cunho trabalhista, ao reservar atenção especial no que toca às relações de trabalho. Não se pode desconsiderar que o Estatuto parte da ratificação da Convenção de Nova Iorque,

7 Vide o Art. $7^{\circ}$, XXXIII, CF: "XXXIII - proibição de trabalho noturno, perigoso ou insalubre a menores de dezoito e de qualquer trabalho a menores de dezesseis anos, salvo na condição de aprendiz, a partir de quatorze anos". 
sendo o primeiro tratado internacional a ser recepcionado nos termos do parágrafo terceiro do art. $5^{\circ}$ da CF, recebendo status de emenda constitucional.

O Estatuto da Pessoa com Deficiência contribuiu significativamente ao reconhecer a liberdade e a autonomia das pessoas com deficiência, admitindo, no campo do trabalho, a possibilidade de trabalho em posição de igualdade, sem nenhum tipo de discriminação, ainda que se reconheça a existência de diversos tipos de barreiras. Portanto, a deficiência não pode servir de motivo para impedir o acesso ao trabalho, e qualquer atitude que limite seus direitos fundamentais, como as revistas sobre seus pertences, deve ser rechaçada.

A ausência de aprofundamento no debate sobre a proporcionalidade do meio adotado, que coloca em xeque o direito à intimidade e à vida privada de todos os trabalhadores, pode comprometer a efetividade dos preceitos constitucionais apontados.

Ademais, não se pode afastar a possibilidade de ser encontrado nas fiscalizações algum tipo de objeto que diga respeito apenas ao empregado. Nesse ponto, cabe retornar a outro questionamento inicialmente problematizado: seria possível o tomador de serviços despedir o empregado caso encontre um entorpecente nos pertences do empregado, ainda que nunca o tenha consumido no local de trabalho?

Para essa pergunta, o art. 482 da CLT $^{8}$ responde ao apresentar taxativamente as hipóteses capazes de fundamentar uma justa causa, o que não incluiria qualquer tipo de droga nociva encontrada nos pertences pessoais do empregado, sem causar prejuízo ao empregador, que só foi constatado a partir da revista praticada no momento da fiscalização. A alínea "f" poderia gerar dúvida porquanto traz a ideia de "embriaguez habitual ou em serviço", mas esta hipótese está relacionada com o uso (seja álcool ou outro tipo de droga), não devendo ser aplicada quando o empregado estiver simplesmente portando o objeto.

O simples fato de portar a droga nociva não pode ser razão para suscitar estigma e/ou preconceito, a ponto de dispensar o empregado de forma discriminatória. Em decisão ligada à questão debatida, o TRT da $17^{\text {a }}$ Região reverteu uma demissão por justa causa em rescisão indireta no caso em que se constatou, através do exame de urina realizado de forma rotineira, que o empregado havia consumido maconha. Conforme decidido, considerou-se que, ainda que fosse caso de dependência de maconha, não caberia penalidade de justa causa, mas sim o direcionamento ao tratamento médico.

8 Vide art. 482 da CLT: “Art. 482. Constituem justa causa para rescisão do contrato de trabalho pelo empregador: a) ato de improbidade; b) incontinência de conduta ou mau procedimento; c) negociação habitual por conta própria ou alheia sem permissão do empregador, e quando constituir ato de concorrência à empresa para a qual trabalha o empregado, ou for prejudicial ao serviço; d) condenação criminal do empregado, passada em julgado, caso não tenha havido suspensão da execução da pena; e) desídia no desempenho das respectivas funções; f) embriaguez habitual ou em serviço; g) violação de segredo da empresa; h) ato de indisciplina ou de insubordinação; i) abandono de emprego; j) ato lesivo da honra ou da boa fama praticado no serviço contra qualquer pessoa, ou ofensas físicas, nas mesmas condições, salvo em caso de legítima defesa, própria ou de outrem; $k$ ) ato lesivo da honra ou da boa fama ou ofensas físicas praticadas contra o empregador e superiores hierárquicos, salvo em caso de legítima defesa, própria ou de outrem; 1 ) prática constante de jogos de azar. $\mathrm{m}$ ) perda da habilitação ou dos requisitos estabelecidos em lei para o exercício da profissão, em decorrência de conduta dolosa do empregado. Parágrafo único - Constitui igualmente justa causa para dispensa de empregado a prática, devidamente comprovada em inquérito administrativo, de atos atentatórios à segurança nacional. 
EMENTA: 1) MACONHA. DEPENDÊNCIA. NECESSIDADE DE TRATAMENTO. NÃO CABIMENTO DE PENALIDADE DISCIPLINAR. A dependência de maconha é considerada doença (CID-10, F12.2). Diante de tal particularidade, o empregador deveria fornecer o devido tratamento a seu empregado. Os mesmos fundamentos utilizados para afastar a justa causa em relação ao alcoólatra também se amoldam ao dependente da maconha [...]. O problema da droga é algo que interessa a toda coletividade, não apenas a determinado ambiente de trabalho [...]. A dependência de maconha deve ser considerada como patologia, não como uma punição a quem já está vitimado de grave doença [...]. (TRT - 17 - RO: 0081500-61.2006.5.17.0008, Relator: Cláudio Armando Couce de Menezes. Data de Publicação: 9/9/2009).

O desembargador do caso, Cláudio Armando Couce de Menezes, reconhecendo o problema da droga como algo que interessa à coletividade, sustentou que o vício não é motivo legal que justifique a penalidade mais grave da justa causa, devendo o empregado ser encaminhado ao tratamento médico. Segundo o relator, a prevenção ao uso de drogas deve ser estimulada a fim de valorizar os trabalhadores, que não podem ser tratados como objetos.

Evidentemente, a relação de trabalho não pode ser considerada uma "carta branca" legitimadora para a violação dos direitos fundamentais dos trabalhadores, que não perdem o direito à intimidade e à vida privada ao entrarem no ambiente de trabalho, empresarial ou doméstico, o que demonstra que a manifestação do poder fiscalizatório a partir das revistas aos pertences pessoais precisa ser repensada.

\section{REPARAÇÃO CIVIL DO DANO A PARTIR DA REFORMA TRABALHISTA}

No silêncio da lei que conduz à aceitação da normal e regular inspeção em pertences e armários dos empregados, debruça-se agora sobre as consequências verificadas quando o empregador não respeitar os critérios fixados pela jurisprudência, analisando-se a fixação do valor compensatório, à luz das alterações promovidas pela Lei $n^{\circ} 13.467 / 2017$, no caso de violação ao interesse juridicamente tutelado.

Sabe-se que em qualquer convívio social as relações entre os indivíduos assumem diferentes formas, as quais vão de "cooperação até à competição e à violência. Cooperação e conflito justapõem-se: ora somos parceiros, ora adversários" (MENDONÇA, 2007, p. 89). É neste ambiente que surge o dever de responsabilizar quando um interesse juridicamente tutelado é violado.

Ainda que para os empregadores a revista nos pertences pessoais dos empregados possa trazer um fator positivo (proteção patrimonial), o meio utilizado, reconhecidamente, apresenta forte aspecto negativo, o que torna pertinente ponderar quanto ao direito à compensação civil, uma vez que, no cenário apresentado, a esfera extrapatrimonial dos indivíduos é profundamente afetada.

Ao violar a intimidade e a vida privada do funcionário, o empregador estaria afrontando direitos fundamentais daquele, ocasionando, dessa forma, uma obrigação de reparar eventuais 
danos de natureza extrapatrimonial experimentado. O poder fiscalizatório, quando exercido além dos limites constitucionais, representa ato ilícito, sendo o dano o principal reflexo dessa ilicitude.

Nesse sentido, quanto aos atos ilícitos:

O art. 186 do Código Civil consagra o princípio da incolumidade das esferas jurídicas, impondo a todos os sujeitos de direito a noção de nemimem laedere, ou seja, o dever geral de não causar dano a quem quer que seja [...]. O princípio da incolumidade das esferas jurídicas tem assento constitucional, pois o art. $5^{\circ}$ de nosso texto fundamental consagra entre os direitos e garantias fundamentais, considerando-os invioláveis, a intimidade, a vida privada, a honra e a imagem das pessoas, assegurando o direito a indenização pelo dano material ou moral decorrente de sua violação (inciso X), além do direito de resposta, proporcional ao agravo, sem prejuízo de indenização por dano material, moral ou à imagem (inciso V). (EHRHARDT JÚNIOR, 2012, p. 437).

No caso em análise, verifica-se um dano moral, já que é atingido um bem incorpóreo, relacionado a aspectos inerentes à personalidade do empregado (intimidade e vida privada).

Segundo Caio Mário da Silva (1996, p. 88), o dano moral representa

[...] ofensa a direitos de natureza extrapatrimonial - ofensas aos direitos integrantes da personalidade do indivíduo, como também ofensas à honra, ao decoro, à paz interior de cada um, às crenças íntimas, aos sentimentos afetivos de qualquer espécie, à liberdade, à vida, à integridade.

Seguindo o mesmo raciocínio, leciona Mauro Schiavi que o conceito de dano moral representa "todo o dano à pessoa, seja no aspecto interior (honra, intimidade, privacidade), bem como o aspecto exterior (imagem, boa-fama, estética), que não tenha natureza econômica, e que abale a dignidade da pessoa" (SCHIAVI, 2007, p. 62). Com esses autores contribui Maria Celina Bodin de Moraes, fundamentada na violação de algum dos substratos da dignidade da pessoa humana (igualdade, liberdade, integridade psicofísica e a solidariedade), para quem:

[...] toda e qualquer circunstância que atinja o ser humano em sua condição humana, que (mesmo longinquamente) pretenda tê-lo como objeto, que negue a sua qualidade de pessoa, será automaticamente considerada violadora de sua personalidade e, se concretizada, causadora de dano moral a ser reparado. [...]. A simples violação de uma situação jurídica subjetiva extrapatrimonial (ou de um "interesse não patrimonial") em que esteja envolvida a vítima, desde que merecedora da tutela, será suficiente para garantir a reparação. (MORAES, 2009, p. 188).

Ressalte-se que a Lei ${ }^{\circ} 13.467 / 2017$, responsável pela atual reforma trabalhista, introduziu o título II-A (art. 223-A e seguintes) quanto aos danos de natureza extrapatrimonial à CLT. O art. 223-C $\mathrm{C}^{9}$ é expresso ao tutelar a intimidade da pessoa física, trazendo uma grande contribuição para

9 Vide o art. 223-C da CLT: "A honra, a imagem, a intimidade, a liberdade de ação, a autoestima, a sexualidade, a saúde, o lazer e a integridade física são os bens juridicamente tutelados inerentes à pessoa física”. 
o debate. Importante destacar que o rol apresentado no dispositivo é meramente exemplificativo, logo, ocorrendo violação a outro direito da mesma natureza que não esteja expresso, este será igualmente protegido.

O art. 223-C expôs a aplicação exclusiva dos dispositivos presentes no título II-A da CLT à reparação de danos de natureza extrapatrimonial, porém, aqui, defende-se a aplicação subsidiária do direito comum por força do art. $8^{\circ}$ da CLT, a fim de garantir a proteção integral ao direito violado.

Cumpre lembrar que o CC/2002 vigente "introduziu no art. 187 a noção de abuso de direito, definindo-o como ato que excede manifestamente os limites impostos pelo seu fim econômico ou social, pela boa-fé ou pelos bons costumes" (EHRHARDT JÚNIOR, 2012, p. 438). Nesse campo, seria possível compreender que os atos de inspeção praticados pelo empregador ou seus prepostos sobre os pertences pessoais dos trabalhadores ao longo da relação trabalhista representariam um claro abuso de direito.

Percebendo o abuso de direito, a responsabilidade no caso deve ser encarada como objetiva, já que não se exige o elemento subjetivo (culpa ou dolo) para se considerar o dever de indenizar.

Ao tratar do art. 187 do CC/2002, Sérgio Cavalieri Filho (2009, p. 152) argumenta:

Depreende-se da redação desse artigo, em primeiro lugar, que a concepção adotada em relação ao abuso de direito é objetiva, pois não é necessária a consciência de se excederem, com o seu exercício, os limites impostos pela boa-fé, pelos bons costumes e pelo fim social ou econômico do direito; basta que se excedam esses limites.

Ao agir com excesso na fiscalização no ambiente de trabalho, o empregador assume o risco e se responsabiliza objetivamente, independentemente da intenção, por eventuais danos causados aos empregados, nos termos do art. 187. Como visto, a revista sobre os pertences pessoais promovidas pelo tomador de serviços extrapola o poder fiscalizatório, desrespeitando os limites impostos pelos direitos personalíssimos, bem como os limites impostos pelo próprio contrato de trabalho, expondo o empregador a condições vexatórias.

Eugênio Facchini Neto $(2010$, p. 24) foi preciso ao ponderar quanto à responsabilidade e asseverar que esta

[...] não é mais a contrapartida de um proveito ou lucro particular, mas sim a consequência inafastável da atividade em geral [...]. Sua aplicação não mais supõe uma atividade empresarial, a exploração de uma indústria ou de um comércio, ligando-se, ao contrário, a qualquer ato do homem que seja potencialmente danoso à esfera jurídica de seus semelhantes. Concretizando-se tal potencialidade, surgiria a obrigação de indenizar.

Assim, no caso em análise, verifica-se o dano moral a partir da violação da integridade psicofísica do empregado, sem que seja necessário avaliar a intenção de prejudicar do ofensor. 
Contudo, insta perceber a relação de causalidade e efeito entre a conduta do empregador e o dano, para surgir o direito à indenização.

No caso da prática das inspeções sobre os pertences, o desrespeito à intimidade e à vida privada que abala a dignidade da pessoa humana gera direito à indenização. Aqui, a violação ao interesse tutelado configura-se independentemente dos efeitos por ele produzidos, que, ademais, não são passíveis de demonstração. $\mathrm{O}$ ato ilícito já se caracteriza pela imposição das revistas íntimas promovidas pelo empregador, deixando clara a presença do nexo de causalidade, visto que o dano não ocorreria se não fosse a conduta indevida.

Alexandre Agra Belmonte (2014, p. 41) ressalta que "a invasão presencial ou virtual da vida privada da pessoa, de seu relacionamento familiar, do tipo de amizades que mantém e dos lugares que frequenta, ensejam a caracterização do dano moral".

Quanto à quantificação do valor indenizatório, ainda que mereça críticas, a Lei 13.467/2017 introduziu o art. 223- $\mathrm{G}^{10}$, o qual, no caput, apresenta critérios para que o magistrado considere no ato de apreciar o pedido de natureza extrapatrimonial. No parágrafo primeiro, trouxe uma tarifação para fixar o quantum indenizatório.

Ainda que mereça discussões quanto à (in)constitucionalidade do tabelamento apresentado no art. 223-G, este dispositivo está vigente e utiliza um critério de quantificação que propõe quatro limites com base no último salário contratual do empregado.

Nesse sentido, a fixação do valor a compensar os danos advindos de uma revista íntima ou a pertences pessoais dos empregados deverá ser avaliada diante do caso concreto, não sendo possível afirmar, a priori, se o dano é de natureza leve, média, grave ou gravíssima. Alguns elementos decisivos para o arbitramento, no caso desse tipo de fiscalização abusiva, serão justamente a natureza do bem jurídico tutelado (a intimidade e a vida privada dos obreiros), a extensão e a duração da ofensa (as revistas foram suportadas por dias, meses ou anos), bem como as condições em que ocorreu a ofensa (o ato ilícito era praticado na vista de outros empregados e clientes ou em local reservado).

Não se pode desprezar a função pedagógica no momento de fixar o montante devido, de forma a desestimular o ofensor à reprodução do comportamento ilícito. Vale dizer, há de se viabilizar uma ação preventiva, garantindo verdadeiro caráter publicista, já que protege a coletividade de futuras repetições danosas. Esse caráter foi reconhecido na reforma trabalhista ao se introduzir o parágrafo terceiro ${ }^{11}$ no art. $223-\mathrm{G}$, que possibilitou ao magistrado majorar ao dobro

10 Vide art. 223-G, caput e $\S 1^{\circ}$ da CLT: “Art. 223-G. “Ao apreciar o pedido, o juízo considerará: I - a natureza do bem jurídico tutelado; II - a intensidade do sofrimento ou da humilhação; III - a possibilidade de superação física ou psicológica; IV - os reflexos pessoais e sociais da ação ou da omissão; V - a extensão e a duração dos efeitos da ofensa; VI - as condições em que ocorreu a ofensa ou o prejuízo moral; VII - o grau de dolo ou culpa; VIII - a ocorrência de retratação espontânea; IX - o esforço efetivo para minimizar a ofensa; X - o perdão, tácito ou expresso; XI - a situação social e econômica das partes envolvidas; XII - o grau de publicidade da ofensa. $\S 1^{\circ} \mathrm{Se}$ julgar procedente o pedido, o juízo fixará a indenização a ser paga, a cada um dos ofendidos, em um dos seguintes parâmetros, vedada a acumulação: I - ofensa de natureza leve, até três vezes o último salário contratual do ofendido; II - ofensa de natureza média, até cinco vezes o último salário contratual do ofendido; III - ofensa de natureza grave, até vinte vezes o último salário contratual do ofendido; IV - ofensa de natureza gravíssima, até cinquenta vezes o último salário contratual do ofendido".

11 Vide art. 223-G, $\S 3^{\circ}$, da CLT: "Na reincidência entre partes idênticas, o juízo poderá elevar ao dobro o valor da indenização". 
o valor compensatório nos casos de reincidência entre partes idênticas.

A valoração pelo magistrado mostra-se essencial para assegurar uma compensação satisfativa, ainda que impossível retornar ao estado anterior no caso do dano de natureza extrapatrimonial. Por meio da experiência, o prudente arbítrio será capaz de estabelecer um montante que, ao mesmo tempo, sirva de compensação ao empregado e apresente, também, um caráter preventivo.

Oportuno registrar que não resta dúvida quanto à competência para julgar o dano moral decorrente dos infortúnios das relações de trabalho. A Emenda Constitucional $n^{\circ} 45$, que tratou da Reforma do Judiciário, incluiu no art. 114 da Constituição o inciso VI ${ }^{12}$, deixando clara a competência da Justiça do Trabalho, o que representou uma importante inovação. No mesmo sentido está a súmula 392 do TST $^{13}$.

O reconhecimento da competência da Justiça do Trabalho para dirimir as controvérsias que envolvam dano moral impactará no prazo prescricional, já que a CF/1988 e a CLT apresentam disciplina própria sobre o tema. $\mathrm{O}$ art. $7^{\circ}$, inciso $\mathrm{XXIX}^{14}$, estabelece o prazo de cinco anos para os trabalhadores urbanos e rurais proporem a ação quanto aos créditos resultantes das relações de trabalho, até o limite de dois anos após a extinção do contrato de trabalho.

Quanto ao dispositivo da CLT, ainda que disserte no mesmo sentido da Carta Magna, cumpre destacar que a Lei ${ }^{\circ} 13.467 / 2017$ corrigiu uma atecnia presente no caput do art. 11, não mais prevendo a expressão "direito", mas sim “pretensão", visto que a prescrição está relacionada com a perda da pretensão, a qual não se confunde com o direito propriamente dito em discussão.

Embora a responsabilidade civil, decorrente das revistas perpetradas pelo empregador, apresente-se como mecanismo disponível pelo sistema jurídico brasileiro para a reparação do dano sofrido, inclusive com o prazo prescricional específico de cinco anos nas causas nas relações de trabalho para pleitear os valores devidos, via de regra, o obreiro só recorre ao órgão judiciário a fim de questionar o ato ilícito após a extinção do contrato, isto é, após ter sofrido por muito tempo a invasão à intimidade e à privacidade oriunda das revistas abusivas.

\section{CONCLUSÃO}

O dano representa qualquer prejuízo causado por uma pessoa (física ou jurídica) a outrem, sendo resultado de uma lesão que poderá situar-se no âmbito extrapatrimonial ou patrimonial. Especificamente em relação ao dano moral, deixa-se claro que este ocorrerá quando um bem personalíssimo for atingido, como, por exemplo, a autoestima, a privacidade, a honra e a intimidade.

12 Vide art. 114, VI, da CF: “as ações de indenização por dano moral ou patrimonial, decorrentes da relação de trabalho".

13 Vide súmula 392 do TST: "DANO MORAL E MATERIAL. RELAÇÃO DE TRABALHO. COMPETÊNCIA DA JUSTIÇA DO TRABALHO: Nos termos do art. 114, inc. VI, da Constituição da República, a Justiça do Trabalho é competente para processar e julgar ações de indenização por dano moral e material, decorrentes da relação de trabalho, inclusive as oriundas de acidente de trabalho e doenças a ele equiparadas, ainda que propostas pelos dependentes ou sucessores do trabalhador falecido".

14 Vide art. $7^{\circ}$, XXIX, da CF: "ação, quanto aos créditos resultantes das relações de trabalho, com prazo prescricional de cinco anos para os trabalhadores urbanos e rurais, até o limite de dois anos após a extinção do contrato de trabalho". 
Percebe-se que o TST, diante de uma indeterminação no plano legislativo quanto à extensão do enunciado revista íntima prevista no art. 373-A, VI, da CLT, e na Lei nº 13.271/2016, não incluiu a ideia de revista pessoal no conceito de revista íntima. Dessa maneira, considerou não ter ocorrido o previsto no suporte fático hipotético, ou seja, entendeu que o suporte fático não se concretizou, impossibilitando a aplicação de uma sanção indenizatória.

Realizando uma interpretação a contrario sensu do exposto na ementa, a revista íntima seria aquela realizada de forma discriminada ou a partir do contato físico. Portanto, apenas nessas situações o suporte fático se concretizaria, e, automaticamente, incidiria a norma jurídica de cunho indenizatório.

Diante dos fatos abordados, entende-se que o conceito de revista íntima avançou de modo a abarcar não apenas a inspeção desnude do empregado, passando a incluir as revistas aos bens pessoais portados por ele, seja em bolsas, seja em armários particulares. Ainda que realizada apenas sobre os objetos pessoais dos empregados, poderá ensejar-lhes um dano.

Não pode o empregador valer-se do poder empregatício para justificar o exercício da fiscalização além dos limites constitucionais e legais, sendo o dano o reflexo desse abuso de direito. Reconhecendo que os atos de inspeção praticados pelo empregador ou seus prepostos sobre os pertences pessoais dos trabalhadores configuram abuso de direito nos termos do art. 187 do CC/2002, a responsabilidade na situação deve ser encarada como objetiva.

$\mathrm{O}$ nexo de causalidade está presente quando a conduta do empregador de realizar as revistas sobre os empregados ou seus pertences acarreta-lhes um dano, no caso, lesão à vida privada e à intimidade, direitos fundamentais tutelados constitucionalmente. Do exposto, verificou-se que, ante o monitoramento abusivo, o obreiro terá à disposição o direito de pleitear a proporcional compensação pelos danos de natureza extrapatrimonial sofridos, solução esta já presente no sistema jurídico brasileiro e que, especificamente no âmbito trabalhista teve recente atualização a partir da vigente Lei ${ }^{\circ} 13.467 / 2017$, não cabendo, para os objetivos deste artigo, aprofundar as críticas ao referido diploma legislativo.

Apesar da ausência de previsão legal expressa especificamente às revistas pessoais, o poder empregatício encontra óbice no próprio contrato de trabalho, bem como nas normas constitucionais, estas representando verdadeiros limites ao empregador. Assim, qualquer forma de inspeção aos bens particulares dos obreiros se mostra atentatória à intimidade, à vida privada e à dignidade humana.

Logo, posicionando-se de forma contrária ao julgado em comento, é possível constatar que a revista íntima não se restringe ao corpo do trabalhador, não havendo como realizar qualquer forma de revista sem que se viole a intimidade dos prestadores de serviços, já que existem diversos meios eficazes para garantir o direito de propriedade do empregador, como, por exemplo, o fornecimento de uniformes padronizados, ressalvando-se, ao mesmo tempo, a dignidade dos obreiros. 


\section{REFERÊNCIAS}

ADAMY, Pedro Augustin. Renúncia a direito fundamental. Malheiros, 2011.

ÁVILA, Humberto. Teoria dos Princípios: da Definição à Aplicação dos Princípios Jurídicos. 11. ed. São Paulo: Malheiros Editores, 2010.

BARROS, Alice Monteiro de. Proteção à intimidade do empregado. São Paulo: LTr, 1997.

BARROSO, Luís Roberto. Curso de direito constitucional contemporâneo: os conceitos fundamentais e a construção do novo modelo. 3. ed. São Paulo: Saraiva, 2011.

BELMONTE, Alexandre Agra. O monitoramento da correspondência eletrônica nas relações de trabalho. 2. ed. atual. e ampl. São Paulo: LTr.

BRASIL. Câmara dos Deputados. Projeto de Lei ñ 583/2007, de 27 de março de 2007. Dispõe sobre a proibição de revista íntima de funcionárias nos locais de trabalho. Disponível em: $<$ https://www.camara.leg.br/proposicoesWeb/fichadetramitacao?idProposicao $=346188>$. Acesso em: 08 set. 2020.

Código Civil. Lei $\mathrm{n}^{\mathrm{o}} 10.405$, de 10 de janeiro de 2002. Disponível em: $<$ https:// presrepublica.jusbrasil.com.br/legislacao/91577/codigo-civil-lei-10406-02>. Acesso em: 29 mar. 2019.

. Constituição (1988). Constituição da República Federativa do Brasil. Disponível em: <http://www.planalto.gov.br/ccivil_03/Constituicao/Constituicao.htm>. Acesso em: 29 mar. 2019.

. Decreto-Lei $\mathrm{n}^{\circ} 5.452$, de $1^{\circ}$ de maio de 1943 . Aprova a consolidação das leis do trabalho. Disponível em: <http://www.planalto.gov.br/ccivil_03/decreto-lei/Del5452.htm>. Acesso em: 29 mar. 2019.

. Lei $\mathrm{n}^{0} 13.271$, de 15 de abril de 2016. Dispõe sobre a proibição de revista íntima de funcionárias nos locais de trabalho e trata de revista íntima em ambientes prisionais. Disponível em: <http:/www.planalto.gov.br/ccivil_03/_Ato2015-2018/2016/Lei/L13271.htm>. Acesso em: 29 mar. 2019.

.Tribunal Regional do Trabalho. Recurso Ordinário nº 0001226-83.2011.5.19.0007. Relator: Relator João Leite. Disponível em: $<$ https://www.trt19.jus.br/consultaProcessual/docs/ apresentaRelatorioAcordao/1226/2011/7/69/1>. Acesso em: 25 abr. 2019.

. Tribunal Regional do Trabalho/ES. Recurso Ordinário n⿳00081500-

61.2006.5.17.0008. Relator: Cláudio Armando Couce de Menezes. Disponível em: $<$ https://trt-17.jusbrasil.com.br/jurisprudencia/695601743/recurso-ordinario-trabalhistaro-0081500-61.2006.5.17.0008/>. Acesso em: 25 abr. 2019.

. Tribunal Superior do Trabalho. ARR no 1111-68.2012.5.09.0892. Relator: Relator Mauricio Godinho Delgado. Brasília, DF, 27 de fevereiro de 2019. Diário Oficial da União. 
Brasília, $1^{\circ}$ mar. 2019.

. Tribunal Superior do Trabalho. ARR no 640-34.2011.5.09.0004. Relator: Relator: Ministro Walmir Oliveira da Costa. Brasília, DF, 21 de novembro de 2018. Diário Oficial da União. Brasília, 23 nov. 2018.

.Tribunal Superior do Trabalho. Recurso de Revista $n^{0}$ 623-62.2011.5.09.0015. Relator: Relator Ministro: Alberto Luiz Bresciani de Fontan Pereira. Brasília, DF, 17 de setembro de 201. Diário Oficial da União. Brasília, 20 set. 2013.

CAVALIERI FILHO, Sérgio. Programa de responsabilidade civil. 8. ed. 3. reimpr. São Paulo: Atlas, 2009.

COMISSÃO INTERAMERICANA DE DIREITOS HMANOS. Pacto de São José da Costa Rica. 1969. Disponível em: $<$ https://www.cidh.oas.org/basicos/portugues/c.convencao americana.htm>. Acesso em: 13 mai. 2020.

CUNHA JÚNIOR, Dirley da. Curso de Direito Constitucional. 3. ed. rev. ampliada e atualizada, Salvador: JusPodivm, 2009.

DELGADO, Gabriela Neves. Direito Fundamental ao trabalho digno. São Paulo: LTr, 2006.

EHRHARDT JÚNIOR, Marcos. Direito Civil - LICC e Parte Geral. Salvador: JusPodivm, 2012, vol. I.

FACCHINI NETO, Eugênio. Da responsabilidade civil no novo código. In: Revista do Tribunal Superior do Trabalho, Porto Alegre, RS, v. 76, n. 1, p. 17-63, jan./mar. 2010.

JORNADA DE DIREITO MATERIAL E PROCESSUAL NA JUSTIÇA DO TRABALHO, 1., 2007, Brasília. ENUNCIADOS APROVADOS. Brasília: Granadeiro Advocacia, 2007. 16 p. Disponível em: <http://www.granadeiro.adv.br/arquivos_pdf/enunciados_jornadaTST.pdf $>$. Acesso em: 21 fev. 2020.

MARTINS, Sérgio Pinto. Direito do trabalho. 25. ed., São Paulo: Atlas, 2009.

MENDONÇA, Luis Correia. Vírus autoritário e processo civil. In: Julgar. n. 1. p. 67-98. Coimbra, jan.-abr. 2007.

MONTEIRO, Washington de Barros. Curso de direito civil. V. 1: parte geral. 39. ed. rev. e atual. por Ana Cristina de Barros Monteiro França Pinto, São Paulo: Saraiva, 2003.

MORAES, Alexandre de. Direitos humanos fundamentais: teoria geral, comentários aos arts. $1^{\circ}$ e $5^{\circ}$ da Constituição da República Federativa do Brasil, doutrina e jurisprudência. 6. ed., São Paulo: Atlas, 2005.

MORAES, Maria Celina Bodin de. Danos à pessoa humana: uma leitura civil-constitucional dos danos morais. Rio de Janeiro: Renovar, 2009.

NASCIMENTO, Amauri Mascaro. Curso de direito do trabalho: história e teoria geral do 
direito do trabalho: relações individuais e coletivas do trabalho. 21. ed. rev. e atual., São Paulo: Saraiva, 2006.

NUNES, Rosana Marques. A revista íntima como cláusula restritiva de direitos fundamentais no Direito do Trabalho. São Paulo: LTr, 2011.

ORGANIZAÇÃO DAS NAÇÕES UNIDAS (Rio). Unic. Declaração Universal dos Direitos Humanos. 2009. Disponível em: <https://nacoesunidas.org/wp-content/uploads/2018/10/DUDH. pdf>. Acesso em: 13 mai. 2020.

PEREIRA, Caio Mário da Silva. Responsabilidade Civil. 8. ed., Rio de Janeiro: Forense, 1996.

PESSOA, Flávia Moreira Guimarães. A dignidade da pessoa humana e o direito do trabalho. In: Revista Ciência Jurídica do Trabalho, ano 12, n. 69, mai./jun. 2008. Belo Horizonte: RCJ Edições Jurídicas Ltda., p. 195/207, 2008.

RIBAR, Geórgia. Os princípios da dignidade da pessoa humana, da igualdade e o princípio da não discriminação na proteção contra a discriminação na relação de emprego. In: Revista LTr, São Paulo: LTr, no 9.

SCHIAVI, Mauro. Ações de reparação por danos morais decorrentes da relação de trabalho: os novos desafios da justiça do trabalho após o Código Civil de 2002 e a emenda constitucional 45/2004. São Paulo: LTr, 2007.

SILVA, Leda Maria Messias da. Monitoramento de e-mails e sites, a intimidade do empregado e o poder de controle do empregador: abrangência e limitações. In: Revista LTr. São Paulo: LTr, $\mathrm{n}^{\mathrm{o}} 1,2006$.

SOUSA, Rabindranath Valentino Aleixo Capelo de. O direito geral da personalidade. Coimbra: Coimbra, 1995.

TUPINAMBÁ, Carolina. Danos extrapatrimoniais decorrentes das relações de trabalho. São Paulo: LTr, 2018.

VIDAL, Bernardo Raposo; ANELLO, Gustavo Lacerda. A sujeição do trabalhador à revista pessoal pelo empregador: uma análise do Enunciado 15 da $1^{\mathrm{a}}$ Jornada de Direito Material e Processual na Justiça do Trabalho. In: Revista Ciência Jurídica do Trabalho, ano 12, n. 72, nov./dez. 2008. Belo Horizonte: RCJ Edições Jurídicas Ltda, 2008, p. 103/116.

Como citar: EHRHARDT JUNIOR, Marcos. MARTINS, Luiz Phillipe de Oliveira Gomes. A polêmica sobre a (im)possibilidade de revista em bolsas e armários na jurisprudência do TST . Scientia Iuris, Londrina, v. 24, n. 3, p. 73-97, nov. 2020. DOI: 10.5433/2178-8189.2020v24n3p73. ISSN: $2178-8189$.

Recebido em: $12 / 07 / 2020$

Aprovado em: 11/09/1010 